Association for Information Systems

AIS Electronic Library (AISeL)

UK Academy for Information Systems

Conference Proceedings 2019

UK Academy for Information Systems

Spring 4-10-2019

\title{
Explaining Technology Adoption with Financial Motivation
}

Joseph Budu

Ghana Institute of Management and Public Administration, josbudu@gimpa.edu.gh

Becky Bentil

MountCrest Institute of Technology, bbentil@gmail.com

Follow this and additional works at: https://aisel.aisnet.org/ukais2019

\section{Recommended Citation}

Budu, Joseph and Bentil, Becky, "Explaining Technology Adoption with Financial Motivation" (2019). UK Academy for Information Systems Conference Proceedings 2019. 41.

https://aisel.aisnet.org/ukais2019/41

This material is brought to you by the UK Academy for Information Systems at AIS Electronic Library (AISeL). It has been accepted for inclusion in UK Academy for Information Systems Conference Proceedings 2019 by an authorized administrator of AIS Electronic Library (AISeL). For more information, please contact elibrary@aisnet.org. 


\title{
Explaining Technology Adoption with Financial Motivation
}

Research-in-progress

Joseph Budu

\begin{abstract}
Several theories and their variant extensions have been posited to explain or to suggest factors that influence technology adoption. However, these theories seem inadequate in certain scenarios. For instance, none of such technology adoption theories identify or account for the possible influence of external non-personal and non-technology incentives or rewards or compensation on persons faced with the choice to accept or use a technology. However, existing psychology research posits a positive correlation between the offer of financial incentives and task. Therefore, this paper purposes to uncover the philosophical and theoretical underpinnings to this suggested relationship, and also to provide observable empirical evidence in support.
\end{abstract}

Keywords: technology adoption, financial motivation, qualitative research

\section{Introduction}

The acceptance and use of new technology is not an exhausted issue in information systems research. This observation is evidenced by the many theories and their variant extensions that attempt either to explain or to suggest factors that influence technology adoption. Despite their utility, these theories still harbour some inadequacies which yearn for fixing. Specifically, these theories have the understood assumption that people will accept and use technology because of factors pertaining to the technology in question, social conditions, and some personal considerations. Arguably, none of such technology adoption theories identify or account for the possible influence of external non-personal and non-technology incentives or rewards or compensation on persons faced with the choice to accept or use a technology (see Rondan-Cataluna, Arenas-Gaintan, \& Ramirez-Correa, 2015 for a comprehensive review of technology adoption theories). Meanwhile there are some contexts in which technology adoption could be considered a task; consider an advertising company contracting an individual to install a digital advertising screen in her vehicle. In such a scenario, the factors posited by extant technology adoption theories become inadequate because that individual may consider factors like task-related compensation. Further, existing psychology research posits a positive correlation between the offer of financial incentives and task performance (Becker, Clement, \& 
Schaedel, 2010). Therefore, this paper argues that it is compensation, especially financial compensation can influence technology adoption. This study thus purposes to uncover the philosophical and theoretical underpinnings to this suggested relationship, and also to provide observable empirical evidence in support.

Addressing consumers' economic motivations for accepting technology is not a minor issue because of the glaring evidence which points to positive correlations they have with task performance (see Becker, Clement, \& Schaedel, 2010). This study makes two main contributions to technology acceptance research in seeking to explain this relationship. First, the study provides alternate explanations for the acceptance and use of new technology. Given Fishbein \& Ajzen's (1975) observation that many variables affect the choice of how and when users will use a new technology, focusing on only the extant factors is a way of blinding ourselves to other working factors like financial incentives. Therefore, this paper in responding to calls for alternative theoretical mechanisms in information technology adoption research (see Bagozzi, 2007; Venkatesh, Davis, \& Morris, 2007), argues that there is a propensity for people to accept technology not just because it is useful or easy to use, or other people are using it, but because of expected financial incentive. Second, using interpretive epistemology and critical realism ontology, the study presents a case study of a very unique situation in which financial motivation influences the uptake of a new technology. Further, an accompanying in vivo analytical technique is used to extend the frontiers of a traditional technology acceptance theory, the UTAUT (Andersen \& Kragh, 2010). Given the theorising nature of the case study method and in vivo analytical technique, it is plausible to consider the ensuing explanations as improvements in existing explanations for technology acceptance.

\section{Preliminary Literature Review}

Several predictive and explanatory theories of technology adoption and/use has been advanced (see Rondan-Cataluna, Arenas-Gaintan, \& Ramirez-Correa, 2015 for a comprehensive review of technology acceptance theories). Despite their usefulness, the myriad of extension and revision attempts suggest their seeming insufficiency to explain either the adoption of certain technologies, or of technologies in certain contexts and situations. For instance, Ozkan, Bindusara, \& Hackney (2010) advance 
perceived advantage - the perception of a system's potential to reduce paperwork and be cost-effective - as an important factor in individual's adoption of electronic payment systems (see Venkatesh, Thong, \& Xu, 2012; Wang \& Lin, 2012; Alotaibi, 2013; Slade, Williams, \& Dwivedi, 2014; Sheng \& Zolfagharian, 2014; Liu, Zhao, Chau, \& Tang, 2015 for more examples of such extensions). Beneath such extensions lie the assumption of a separate human entity deciding to adopt and/use a certain technology. The context of this assumption is pertinent, hence, Venkatesh, Thong, \& $\mathrm{Xu}$ (2012) distinguishes between an individual's adoption of technology within an organisation, and the other outside an organisation i.e. a private consumer, in advancing the UTAUT2 model. Private consumers face peculiar situations like financial risk, price value and motivation (Sheng \& Zolfagharian, 2014; Venkatesh, Thong, \& Xu, 2012).

We may be tempted to forcibly classify such peculiar factors under UTAUT's facilitating conditions - individual's perceptions of the resources and support available to adopt technology (Venkatesh, Morris, Davis, \& Davis, 2003). The implausibility of such attempt, however, is evidenced by the advancement of hedonic motivation and price value as factors for private consumer adoption of technology (Venkatesh, Thong, \& Xu, 2012). Whilst there has been an attempt to extend technology adoption theories with motivation, the focus of such attempts have been insufficient with regards to all its possible forms. Venkatesh et al. (2012) for instance speaks of only hedonic motivation, thus overlooking non-hedonic extrinsic material motivation or rewards. In fact, such forms manifest in several forms as recognition programs, profitsharing programs, pay increase, benefits and incentives (Govindarajulu \& Daily, 2004). The argument here then is that these material forms of motivation can influence private consumers who consider financial risk, and are looking for tangible benefits, to adopt some technology or vice versa.

Such an argument is not far-fetched if we further consider the private consumer in two forms; on one the one hand, the private consumer who is buying/adopting a technology for personal use and to achieve hedonic or even work-related satisfaction, and on the other hand, the private consumer who is acquiring/adopting a technology for financial gain. As Venkatesh et al. (2012) as already demonstrated the existence of hedonic motivation, let us consider its opposite. We know that a person will 
voluntarily act because of gaining a selfish reason after identifying a higher pay-off in a cost-benefit analysis of acting; and a financial pay-off guarantees more action (Darrington \& Howell, 2011, p. 43). We also know that financial incentives shape individual's preferences, and can even destroy her intrinsic motivation (Bowles, 2008). Therefore, direct financial rewards attracting individuals to share their internet service and act as hotspots is not at all trivial (see Becker, Clement, \& Schaedel, 2010). Based on this argument, and attempting to move away from existing theories' limited explanatory or predictive possibilities, triviality and lack of practical value (Garača, 2011), this study advances the third version of the Unified Theory of Acceptance and Use of Technology (UTAUT3).

\section{Proposed Research Methods}

The empirical study will be approached with interpretive epistemology (Walsham, 2006) which suggests the gathering of qualitative data. Intepretivism is important because private consumers may have different conditions that motivate them to adopt technology, and different conceptions concerning such conditions. Thus, the aim to understand how individuals view financial motivation, and why it influences them to adopt technology makes it important to capture subjects' interpretative meanings.

\section{Research Approach}

A case study approach (Cresswell, 2007) will be used to understand the influence of financial motivation in individual's adoption of technology. This issue was conceptualised through observation of the In-Taxi Ad Project (iTAP) being executed by Tech Nation, an Australian/Ghanaian owned technology-based company operating in Ghana (Tech Nation, 2015). iTAP involves the installation of interactive headrest screens showing 'infotainment' to passengers who board commercial vehicles. Drivers who agree to the installation in their vehicles sign an agreement which guarantees monthly financial rewards for ensuring daily operation, and indemnity if the device is broken or lost. To this end this study will delve into Tech Nation's commercial driver recruitment activities and related documents, even on the driver side to understand the mechanisms that enable. In operationalising this approach, purposive sampling will be used to select drivers who will be respondents; these drivers are those who have the screen installed in their cars. 


\section{Data Collection Methods}

Data will be collected from meetings with Tech Nation management and staff, the company's website, and members of driver unions that Tech Nation has approached and installed their digital headrests. Documents like contracts, terms and conditions, and product descriptions and manuals will also be examined to ensure credibility of the interpretive epistemology to be adopted, and the veracity and dependability of the data.

Meetings. Face-to-face meetings will be held with the management and implementation or technical staff of Tech Nation to understand the rationale for giving financial rewards to taxi drivers who subscribe to iTAP, and the impact of such rewards on subscription.

Interviews. 30 taxi drivers who have joined iTAP, and 30 drivers in the same taxi terminals but have not joined iTAP will be interviewed to solicit their reasons for subscribing or otherwise, respectively. The interview data will be coded to reveal the perspectives of the interviewees concerning what influences their adoption decisions.

Website Content Analysis. Videos, audios, images, and text on Tech Nation's website will be analysed for information concerning iTAP. Such data will serve as triangulation and corroborative data for information gathered from interviews and meetings.

Documents. Subscription contracts and service level agreements will be reviewed to verify payment amounts and risk management arrangements between the subscribing drivers and Tech Nation, as corroborative data.

\section{Data Analysis}

Analysis of this study's data will be approached with deductive reasoning (Ven de Ven, 2007). Deduction will be adopted to explain how material rewards influence the uptake of technologies by private individuals outside an organisational setting. The other reasons for technology adoption as proposed by version 2 of the Unified Theory of Acceptance and Use of Technology (see Venkatesh, Thong, \& Xu, 2012) will also be identified from the data and coded using NVivo qualitative analysis software, and their inherent and contextual explanatory inadequacies discussed. 


\section{References (Font Size $=14$ )}

Ajzen, I., \& Fishbein, M. (1980). Understanding Attitudes and Predicting Social Behaviour. Englewood Cliffs, NJ: Prentice-Hall.

2. Alotaibi, M. B. (2013). Determinants of mobile service acceptance in Saudi Arabia: a revised UTAUT model. International Journal of E-Services and Mobile Applications , 5 (3), 43-61.

3. Bagozzi, R. P. (2007). The legacy of the Technology Acceptance Model and a Proposal for a paradigm shift. Journal of the AIS, 8 (4), 244-254.

4. Bateman, M. J., \& Ludwig, T. D. (2003). Managing distribution equality through an adapted incentive program with tiered goals and feedback. Journal of Organisational Behaviour Management, 23, 33-55.

5. Becker, J. U., Clement, M., \& Schaedel, U. (2010). The impact of network size and financial incentives on adoption and participation in new online communities. Journal of Media Economics, 23, 165-179.

6. Bowles, S. (2008). Policies designed for self-interested citizens may undermine 'the moral sentiments': evidence from economic experiments. Science, 320 (5883), 1605-1609.

7. Cresswell, J. W. (2007). Qualitative Inquiry and Research Design. Thousand Oaks, CA: Sage.

8. Darrington, J. W., \& Howell, G. A. (2011). Motivation and incentives in relational contracts. Journal of Financial Management of Property and Construction, 16 (1), 42-51.

9. Davis, F. (1989). Perceived usefulness, perceived ease of use, and user acceptance of information technology. MIS Quarterly, 13 (3), 319-340.

10. Fishbein, M., \& Ajzen, I. (1975). Belief, attitude, intention, and behaviour: an introduction to Theory and Research. Reading, MA: Addison-Wesley.

11. Garača, Z. (2011). Factors related to the intended vuse of ERP systems. Management, 16 (2), 23-42.

12. Garbers, Y., \& Konradt, U. (2014). The effect of financial incentives on performance: a quantitative review of individual and team-based financial incentives. Journal of Occupational and Organisational Psychology, 87, 102-137.

13. Gardner, D. G., Van Dyne, L., \& Pierce, J. L. (2004). The effects of pay level on organisation-based self-esteem and performance: a field investigation. Journal of Occupational and Organisational Psychology, 77, 1-16.

14. Goomas, D. T., \& Ludwig, T. D. (2007). Enhancing incentive programs with proximal goals and immediate feedback. Journal of Organisational Behaviour Management, 27, 3368.

15. Govindarajulu, N., \& Daily, B. F. (2004). Motivating employees for environmental improvement. Industrial Management \& Data Systems, 104 (4), 364-372.

16. Herzberg, F. (1966). Work and the nature of man. Cleveland, OH: World.

17. Lawler, E. I. (1973). Motivation in work organisations. Monterey, CA: Brooks/Cole Publishing.

18. Liu, F., Zhao, X., Chau, P. Y., \& Tang, Q. (2015). Roles of perceived value and individual differences in the acceptance of mobile coupon applications. Internet Research, 25 (3), 471-495.

19. Ozkan, S., Bindusara, G., \& Hackney, R. (2010). Facilitating the adoption of e-payment systems: theoretical constructs and empirical analysis. Journal of Enterprise Information Management, 23 (3), 305-325.

20. Rondan-Cataluna, F. J., Arenas-Gaintan, J., \& Ramirez-Correa, P. E. (2015). A comparison of the different versions of popular technology acceptance models. Kybernetes, 44 (5), 788-805.

21. Sheng, X., \& Zolfagharian, M. (2014). Consumer participation in online product recommendation services: augmenting the technology acceptance model. Journal of Services Marketing, 28 (6), 460-470.

22. Slade, E. L., Williams, M. D., \& Dwivedi, Y. K. (2014). Devising a research model to examine adoption of mobile payments: an extension of UTAUT2. The Marketing Review, 14 (3), 310-335.

23. Tech Nation. (2015). About Tech Nation Ghana. Retrieved September 2, 2015, from Tech Nation website: http://technationgh.com/about-tech-nation-ghana/

24. Van de Ven, A.H. (2007). Engaged Scholarship: A Guide for Organisational and Social Research, Oxford, New York, NY. 
25. Venkatesh, V., \& Bala, H. (2008). Technology acceptance model 3 and a research agenda on interventions. Decision Sciences, 39 (2), 273-315.

26. Venkatesh, V., \& Davis, F. D. (2000). A theoretical extension of the technology acceptance model: four longitudinal field studies. Management Science, 46 (2), 186-204.

27. Venkatesh, V., Davis, F. D., \& Morris, M. G. (2007). Dead or Alive? The development, trajectory and future of technology adoption research. Journal of the AIS, 8 (4), 268-286.

28. Venkatesh, V., Morris, M. G., Davis, G. B., \& Davis, F. D. (2003). User acceptance of information technology: toward a unified view. MIS Quarterly, 27 (3), 425-478.

29. Venkatesh, V., Thong, J. Y., \& Xu, X. (2012). Consumer acceptance and use of information technology: extending the Unified Theory of Acceptance and Use of Technology. MIS Quarterly, 36 (1), 157-178.

30. Walsham, G. (2006). Doing Interpretive Research. European Journal of Information Systems, 15 (3), 320-330.

31. Wang, K., \& Lin, C.-L. (2012). The adoption of mobile value-added services. Investigating the influence of IS quality and perceived playfulness. Managing Service Quality, 22 (2), 184-208. 